\title{
Microbial hexuronate catabolism in biotechnology
}

Joosu Kuivanen ${ }^{1}$, Alessandra Biz² and Peter Richard ${ }^{1 *}$ (i)

\begin{abstract}
The most abundant hexuronate in plant biomass is D-galacturonate. D-Galacturonate is the main constituent of pectin. Pectin-rich biomass is abundantly available as sugar beet pulp or citrus processing waste and is currently mainly used as cattle feed. Other naturally occurring hexuronates are D-glucuronate, L-guluronate, D-mannuronate and L-iduronate. D-Glucuronate is a constituent of the plant cell wall polysaccharide glucuronoxylan and of the algal polysaccharide ulvan. Ulvan also contains L-iduronate. L-Guluronate and D-mannuronate are the monomers of alginate. These raw materials have the potential to be used as raw material in biotechnology-based production of fuels or chemicals. In this communication, we will review the microbial pathways related to these hexuronates and their potential use in biotechnology.
\end{abstract}

Keywords: D-Galacturonate, D-Glucuronate, Pectin

\section{Introduction}

D-Galacturonate (D-galUA) is the most abundant hexuronic acid. It is the main monomer of pectin. Pectinrich biomass is an important raw material but it has not attracted much attention. Some examples of pectin-rich biomass are sugar beet pulp (SBP), apple pomace and citrus processing waste (CPW). The potential use of this biomass for the production of fuels and chemicals has been reviewed in the past (Richard and Hilditch 2009; Edwards and Doran-Peterson 2012). The current communication covers new developments.

The worldwide production of sugar beet is about 250 million tons per year. From one ton of beet, about $150 \mathrm{~kg}$ of sugar and about $210 \mathrm{~kg}$ of pressed beet pulp are produced. The pressed beet pulp has a dry matter content of about $20 \%$. Pressed beet pulp is often ensiled and used as cattle feed. The D-galUA content of the dry matter is about 21\% (Micard et al. 1996). Citrus fruit production worldwide is about 115 million tons per year; however only about a third is processed in citrus juice factories, where about $50-60 \%$ of the fruit is CPW. CPW has about

\footnotetext{
*Correspondence: Peter.Richard@vtt.fi

${ }^{1}$ VTT Technical Research Centre of Finland Ltd, PO box 1000, 02044

VTT Espoo, Finland

Full list of author information is available at the end of the article
}

$20 \%$ dry matter, of which $40 \%$ is pectin. Unlike the pectin from SBP, CPW pectin can be used as a food ingredient for gelling purposes. However, the market for food pectin is much lower than the amount of pectin available from CPW.

$\mathrm{D}$-Glucuronate (D-glcUA) is a constituent of the plant cell wall polysaccharide glucuronoxylan (Reis et al. 1994) and of the algal polysaccharide ulvan (Lahaye and Robic 2007). In addition, D-glcUA can be produced through biochemical routes from $\mathrm{D}$-glucose via the myo-inositol oxidation pathway (Moon et al. 2009), which increases the relevance of D-glcUA-converting enzymes from the point of view of biomass processing.

\section{Pectin structure and enzymatic hydrolysis}

Pectins are a group of complex and flexible polymers that are found in plant biomass. They are abundant around growing or dividing plant cells and soft tissues such as fruit peels. The main monomer D-galUA is a common feature in all the pectic polymers, accounting for about $70 \%$ of the overall composition of pectin monomers (Mohnen 2008). Chemical structures of the pectin polymers can be divided into homogalacturonan (HG), the chemically more complex rhamnogalacturonan I (RGI) and substituted HGs such as rhamnogalacturonan II (RG-2) (Fig. 1). HG is also referred to as smooth pectin, 


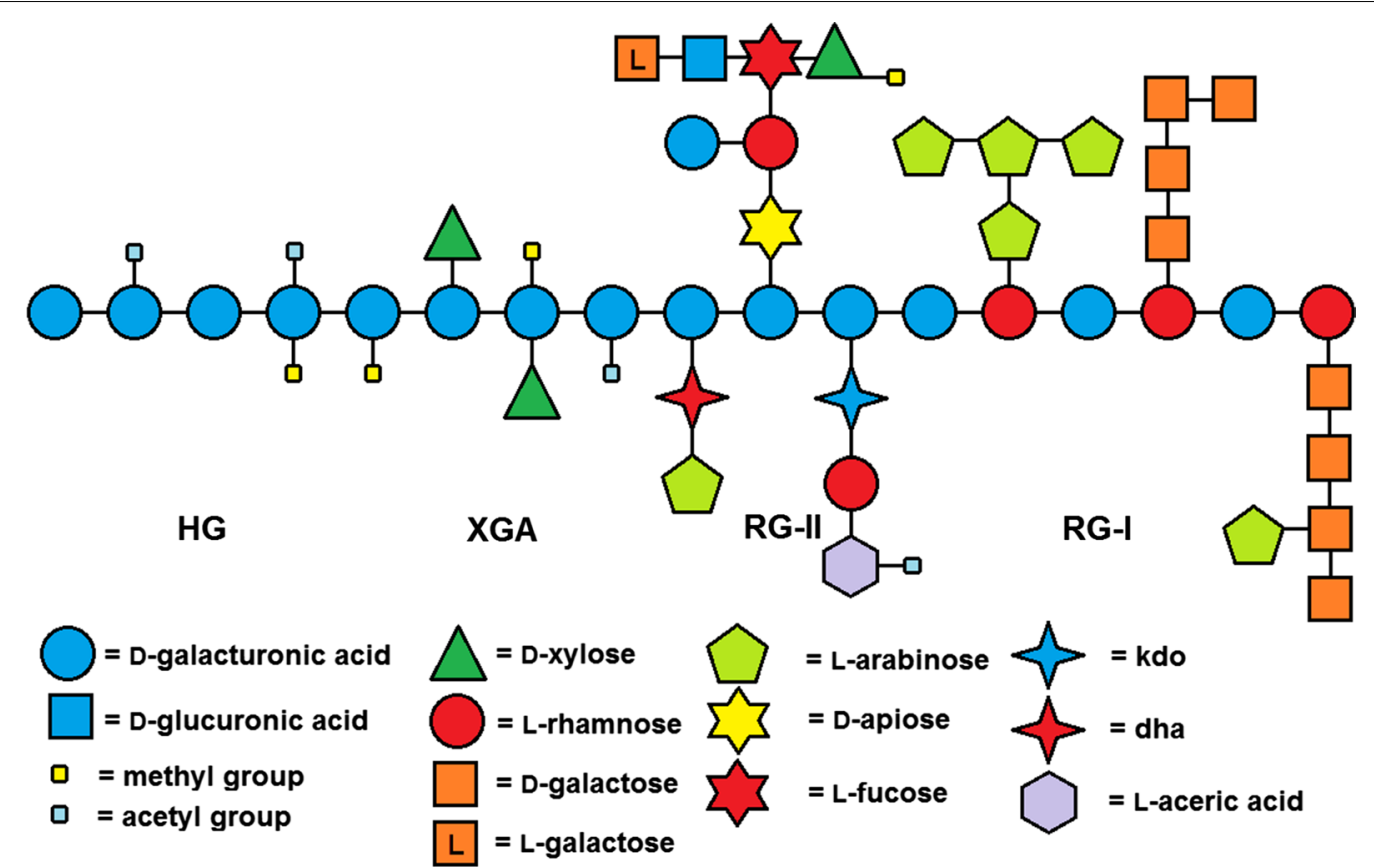

Fig. 1 Structure of the pectic polymers homogalacturonan (HG), xylogalacturonan (XGA) rhamnogalacturonan II (RG-II) and rhamnogalacturonan I (RG-I). Figure from (Kuivanen 2015)

whereas RG-I and substituted HGs are referred to as hairy pectin.

HG consists of $\alpha$-1,4-linked D-galUA units which are partially acetylated and methylesterified (Mohnen 2008). Accounting for about $65 \%$ of pectic polysaccharides, HG is the most common pectin type (Mohnen 2008). RG-I accounts for about $20-35 \%$ of pectin (Mohnen 2008). In contrast to other pectin types, the backbone of RG-I consists of alternating $\alpha-1,2$-linked L-rhamnose and $\alpha-1,4$ linked D-galUA units. In addition, rhamnosyl residues in the RG-I backbone are often attached by side chains containing L-arabinose and D-galactose (Guillon et al. 1989; Colquhoun et al. 1994). Substituted HGs contain pectic heteropolymers with an $\alpha-1,4$-linked D-galUA backbone attached to different side chains. They are classified on the basis of their side chain composition. Rhamnogalacturonan II (RG-II) is the most abundant of the substituted HGs, and it represents about $10 \%$ of pectin (O'Neill et al. 2004). Side chains in RG-II are composed of 12 different monomers including D-galactose, L-galactose, L-arabinose, L-rhamnose, D-xylose, L-fucose, D-apiose, D-galUA, D-glucuronate, 2-keto-3-deoxy-D-lyxo-heptulosaric acid (dha), 2-keto-3-deoxy-D-manno-octulosonic acid (kdo) and L-aceric acid (Mohnen 2008). Other substituted HGs include the less common heteropolysaccharides apiogalacturonan (AP) and xylogalacturonan
(XGA), with D-apiofuranose or D-xylose side chains, respectively (Mohnen 2008).

Being abundant components of biomass, pectic polymers are degraded and the resulting monomers are catabolized by many bacterial and fungal microorganisms. Because the structure of pectin is very diverse, a complex set of pectin-degrading enzymes are produced and secreted by saprophytic microorganisms in order to release the monomers. These enzymes are also collectively referred to as pectic enzymes or pectinases. Pectic enzymes degrading the main chains of HG, RG-I or substituted HG are classified into hydrolases and lyases. Pectic hydrolases include exo- and endo-acting enzymes hydrolysing terminal D-galUA and L-rhamnose units at the non-reducing ends or internal bonds of pectic polymers, respectively (de Vries and Visser 2001; Culleton et al. 2013). For the pectic polymer XGA, specific xylogalacturonan hydrolases are active in the hydrolysis (van der Vlugt-Bergmans et al. 2000). In contrast to hydrolases, pectin-degrading lyases cleave the main chain through a $\beta$-elimination mechanism, forming unsaturated non-reducing ends (de Vries and Visser 2001). In addition to main chain degrading pectic enzymes, an extensive set of accessory enzymes, such as pectin methyl (Khanh et al. 1991) and acetyl (Searlevan Leeuwen et al. 1996) esterases, are needed for complete pectin degradation. Accessory enzymes including arabinofuranosidases, arabinases, galactanases, 
$\beta$-galactosidases, $\beta$-xylosidases, $\alpha$-rhamnosidases and glucuronyl hydrolases are also required for complete pectin degradation (de Vries and Visser 2001).

Saprophytic filamentous fungi, such as Aspergillus niger, are capable of degrading pectic polymers. For example, 66 predicted genes that are possibly involved in pectin degradation are found in the genome of $A$. niger (Culleton et al. 2013), of which 46 were observed to be upregulated in the presence of monomeric pectin constituents or pectic polymers (Martens-Uzunova and Schaap 2009). In addition, $A$. niger is capable of growing on pectin-rich biomass (sugar beet and citrus pulp), pure pectin and many of the monomeric pectin constituents as sole carbon source (Fungal growth database). Pectindegrading enzymes from fungi are also utilised e.g. in the beverage industry, where they are used to improve the juice yields and clarity of the final product.

\section{Microbial pathways for hexuronate catabolism}

D-GalUA is catabolized by different life forms using different catabolic pathways. There are at least two prokaryotic and one eukaryotic pathway in microorganisms for the catabolism of D-galUA. The D-galUA and the D-glcUA pathways are similar in some life forms.

\section{Bacterial pathways for D-galacturonate and D-glucuronate The bacterial isomerase pathways}

In many bacterial species such as Escherichia coli and Bacillus subtilis, D-galUA is catabolized through the isomerase pathway with the genes $u x a C, u x a B, u x a A$, $k d g K$ and $k d g A$. In this pathway, D-galUA is converted to pyruvate and D-glyceraldehyde 3-phosphate, GAP, at the expense of one NADH and one ATP. The $u x a C$ codes for a uronate isomerase converting the $\mathrm{D}$-galUA to $\mathrm{D}$-tagaturonate. The $u x a B$ codes for a $\mathrm{D}$-tagaturonate reductase that forms D-altronate and has a specific requirement for $\mathrm{NADH}$. The $u x a A$ codes for a $\mathrm{D}$-altronate dehydratase that forms 2-keto-3-deoxy gluconate, KDG. KDG is then catabolised to pyruvate and GAP by the enzymes KdgK and KdgA (Fig. 2). The $u x a C, u x a B, u x a A$ and the exuT coding for a $\mathrm{D}$-glcUA transport protein are organized in one operon (Mekjian et al. 1999).

D-GlcUA is catabolised using partly the same enzymes. The first enzyme from the D-galUA pathway, the UxaC, is also used in the first step of the D-glcUA pathway to form $D$-fructuronate. D-Fructuronate cannot be catabolized by $U x a B$ and UxaA. Instead UxuB and UxuA convert $D$-fructuronate to D-mannonate and KDG. The UxuB is a D-fructuronate reductase requiring $\mathrm{NADH}$ and forming D-mannonate. UxuA is a mannonate dehydratase forming KDG, which is the same metabolite as in the D-galUA pathway. The enzymes for the reaction of KDG to KDG6-phosphate and then to pyruvate and GAP, the KDG kinase, KdgK, and KDG-6-phosphate aldolase, KdgA, are used in the D-galUA and D-glcUA pathway. The genes $u x u B$ and $u x u A$ are in a separate operon, the genes $k d g K$ and $k d g A$ are not part of any of these operons. The $k d g A$ is also called $e d a$ and is part of the Entner-Doudoroff pathway as well as of the D-galUA and D-glcUA pathways. The D-galUA and the D-glcUA pathways are different after the UxaC. In the hyperthermophilic bacterium Thermotoga maritima, an enzyme was identified that connects these pathways. This enzyme is a D-tagaturonate- D-fructuronate epimerase, UxaE (Fig. 2). With the aid of this enzyme D-galUA can be metabolized by UxuB and UxuA and D-glcUA by UxaB and UxaA (Rodionova et al. 2012).

The pathway for 5-keto-4-deoxy-galacturonate catabolism also has KDG as an intermediate. 5-Keto-4-deoxygalacturonate is produced from pectin when lyases and not only hydrolases are degrading the pectin. 5-Keto4-deoxy-galacturonate is converted by an isomerase, $\mathrm{KduI}$, to 3-deoxy-D-glycero-hex-2,5-diulosonate, which is subsequently reduced to KDG by the NADH-dependentreductase KduD. This was described in Erwinia chrysanthemi (Condemine and Robert-Baudouy 1991). Homologous genes are also found in other bacteria such as E. coli. The KduD activity was demonstrated in E. coli (Hantz 1977). The E. coli enzymes KduI and KduD were however suggested also to have a role in hexuronate catabolism (Rothe et al. 2013), and $\mathrm{KduD}$ was shown to have activity with steroids (Tubeleviciute et al. 2014). Oligogalacturonate lyases produce 4,5-unsaturated monouronates, which were believed to spontaneously convert to the 5-keto-4-deoxy-galacturonate. This is however a slow process and an enzyme, $\mathrm{KduF}$, was recently identified to catalyse this step (Hobbs et al. 2016) (Fig. 2). 5-Keto-4-deoxy-galacturonate can also originate directly from D-galUA by the action of a dehydratase. D-galUA dehydratases were described for Microscilla and Geobacillus (Groninger-Poe 2014).

\section{The oxidative bacterial pathways}

Some bacteria, such as Agrobacterium tumefaciens and Pseudomonas species, do not have the isomerase pathway but instead use an oxidative pathway (Fig. 3). In this pathway, D-galUA is converted to 2-ketoglutarate and $\mathrm{CO}_{2}$, with the reduction of two $\operatorname{NAD}(\mathrm{P})^{+}$. This pathway is best understood in A. tumefaciens. Here, the first enzyme is the uronate dehydrogenase (Udh), which reduces the D-galUA to galactarolactone using $\mathrm{NAD}^{+}$ as a cofactor. The galactarolactone in solution was identified as galactaro-1,4-lactone (Boer et al. 2010), however the crystal structure of the Udh revealed that it is the galactaro-1,5-lactone that is bound to the active site of the enzyme (Parkkinen et al. 2011). Although 


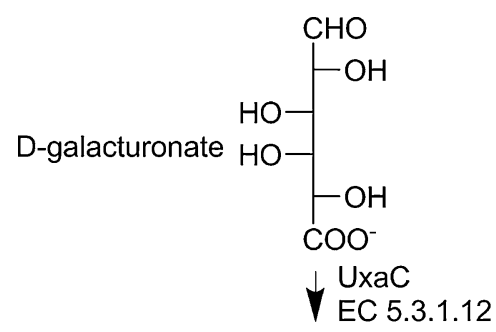<smiles>O=CC(O)C(O)C(O)(O)C(O)(O)C(=O)[O-]</smiles><smiles>O=C([O-])C1=C[C@H](O)[C@H](O)[C@H](O)O1</smiles>

4,5 unsaturated monouronate

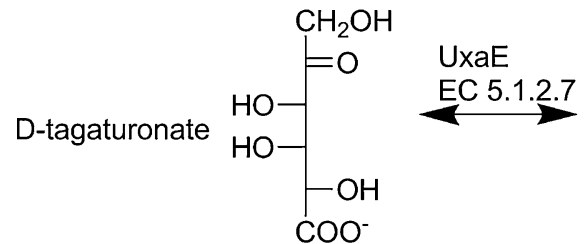
$\downarrow$ UxaC EC 5.3.1.12<smiles>[14CH3][14CH3]</smiles><smiles>O=C(CO)C(O)C(O)(O)C(O)(C(=O)[O-])C(=O)[O-]</smiles>

D-fructuronate<smiles>O=CC(O)C(O)CC(=O)C(=O)O[Na]</smiles>

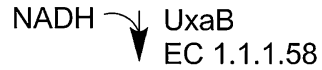

$\mathrm{NADH} \searrow \mathrm{UxuB}$

1.1.1.57

$\downarrow$ Kdul

EC 5.3.1.17<smiles>O=C([O-])C(O)(C(=O)O)C(O)C(O)(O)CO</smiles><smiles>O=C([O-])C(O)(O)C(O)(O)C(O)CO</smiles>

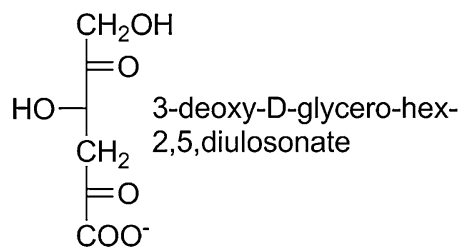

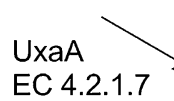

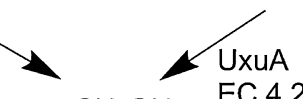<smiles>O=C([O-])C(=O)CC(O)C(O)CO</smiles>
EC 4.2.1.8

D-mannonate

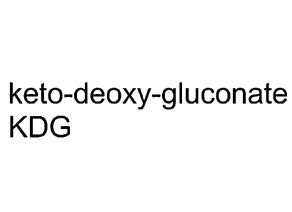

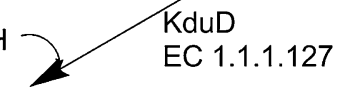<smiles>c1ccccc1</smiles>

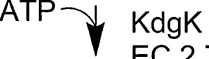

keto-deoxy-gluconate

6-phosphate

$\downarrow \mathrm{KdgA}$ (eda)

$\begin{array}{ll} & \text { EC 4.1.2. } \\ \text { D-glyceraldehyde } & \text { pyruvate } \\ \text { 3-phosphate (GAP) } & \end{array}$

Fig. 2 Bacterial pathways for hexuronate catabolism through keto-deoxy-gluconate, KDG. The pathways for D-galacturonate and D-glucuronate have the enzymes UxaC, KdgK and KdgA in common. The 4,5 unsaturated mono-uronate is the product of lyases acting on polygalacturonate, and DEHU (4-deoxy-L-erythro-5-hexoseulose uronate) is the product of lyases acting on alginate, a copolymer of two uronates, D-mannuronate and L-guluronate

the conversion appeared to be spontaneous, a galactaro $\delta$-isomerase (Gli) was identified, catalysing the reaction from the 1,5-lactone to the 1,4-lactone. The resulting 1,4-lactone was suggested to be the $(2 \mathrm{R}, 3 \mathrm{R}, 4 \mathrm{R}, 5 \mathrm{~S})$ galactaro-1,4-lactone and not the $(2 \mathrm{~S}, 3 \mathrm{~S}, 4 \mathrm{~S}, 5 \mathrm{R})$ isomer (Bouvier et al. 2014). The galactarolactone is then directly converted to the 2-keto-3-deoxy galactarate (3-deoxy-2-keto-L-threo-hexarate) by galactarolactone cycloisomerase (Gci) (Andberg et al. 2012). It was previously assumed that the galactarolactone would have been hydrolysed to galactarate in this pathway and that galactarate dehydratase produces the 2-keto-3-deoxy galactarate (Chang and Feingold 1970). At least in $A$. tumefaciens the shortcut catalysed by Gci is used. The next step is a combined dehydratase and decarboxylase reaction that results in 2-keto-glutarate semialdehyde. The 2-keto-glutarate semialdehyde is then oxidised by an $\mathrm{NADP}^{+}$-dependentdehydrogenase to 2-ketoglutarate. 

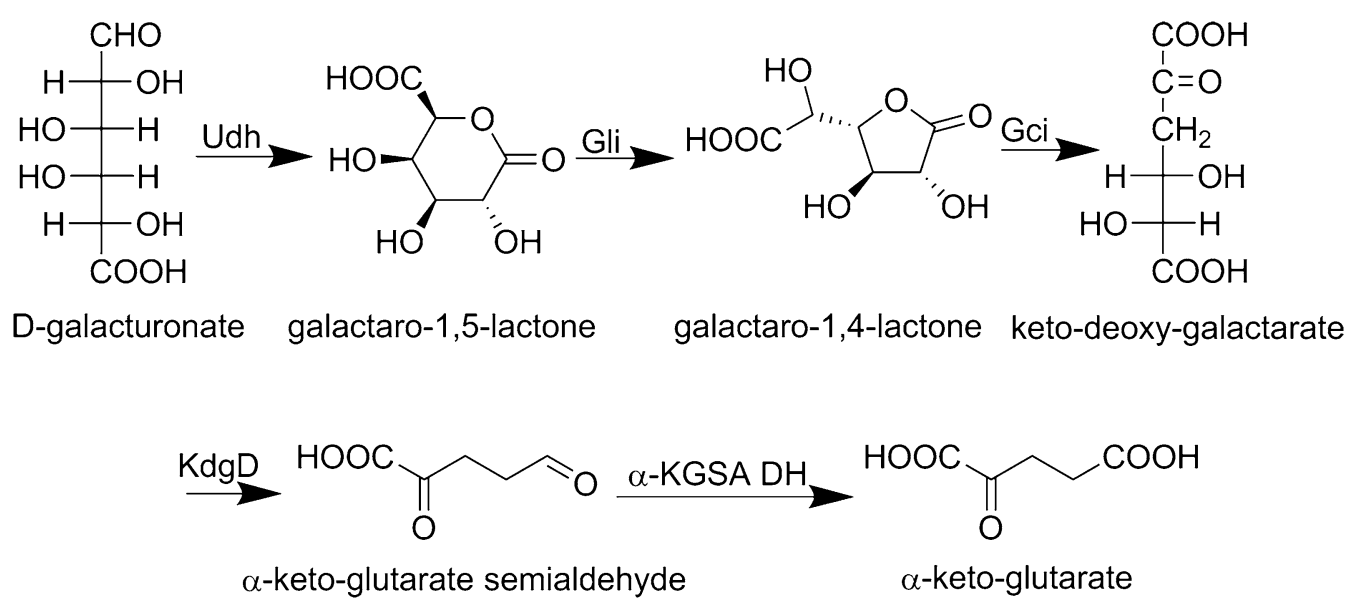

Fig. 3 The bacterial pathway for oxidative galacturonate catabolism. Udh: D-galacturonate dehydrogenase EC 1.1.1.203; Gli: galactarolactone isomerase EC 5.4.1.4; Gci: galactarolactone cycloisomerase EC 5.5.1.27; KdgD: 5-dehydro-4-deoxy-glucarate dehydratase EC 4.2.1.41; a-KGSA DH: 2,5-dioxypentanate dehydrogenase EC 1.2.1.26

Genes for the last two enzymes were first identified in Acinetobacter baylyi (Aghaie et al. 2008). The enzymes of this pathway can be used for the catabolism of D-galUA and D-glcUA. The Udh is unspecific and produces galactarolactone or glucarolactone depending on the substrate. Whether or not the Gli is active with glucarolactone is unclear, but the Gci accepts both lactones as substrate and the reaction product 3-deoxy-2-keto-Lthreo-hexarate is common to both pathways. Recently a novel variant of the oxidative pathway was identified. Two previously uncharacterized lactonases (UxuL and UxuF) were identified that catalyse the ring opening of galactaro-1,5-lactone and glucaro-1,5-lactone to galactarate and glucarate, respectively. The lactonases were not active with the 1,4-lactones (Bouvier et al. 2018).

\section{Pathway for L-guluronate, D-mannuronate and L-iduronate catabolism}

Alginate is a polymer composed of L-guluronate and D-manuronate. The polymer is degraded by the action of alginate lyases, which results in the monomer 4-deoxyL-erythro-5-hexoseulose, DEHU (Fig. 2). In Pseudemonas species DEHU is reduced by an NADPH-dependent reductase to 2-keto-3-deoxy-D-gluconate, KDG. KDG is then phosphorylated and subsequently split by an aldolase to pyruvate and glyceraldehyde 3-phosphate (Preiss and Ashwell 1962). The pathway has been expressed in the yeast S. cerevisiae (Enquist-Newman et al. 2014). The authors identified DEHU reductases from Vibrio splendi$d u s$ and Vibrio harveyi that prefer $\mathrm{NADH}$ as a cofactor, and identified a DEHU transport protein from Asteromyces cruciatus that was active when expressed in yeast (Enquist-Newman et al. 2014).
L-iduronic acid is present in ulvan at a high level (Glasson et al. 2017). It is however not clear what microbial catabolic reactions are responsible for its catabolism.

\section{Fungal pathways}

The fungal pathway for D-galUA was first described in the mould Trichoderma reesei. In this pathway, D-galUA is converted to glycerol and pyruvate at the expense of two NADPH. It consists of an NADPH-dependent D-galUA reductase, Gar1 (Kuorelahti et al. 2005), an L-galactonate dehydratase, Lgd1 (Kuorelahti et al. 2006), a 2-keto-3-deoxy-L-galactonate aldolase, Lga1 (Hilditch et al. 2007) and an NADPH-dependent L-glyceraldehyde reductase, Gld1 (Liepins et al. 2006). The same pathway was also described in Aspergillus niger (Martens-Uzunova and Schaap 2008) and in Botrytis cinerea (Zhang et al. 2011) (Fig. 4a). In $A$. niger, the D-glaUA reductase, GaaA, is unspecific and can also accept NADH as a cofactor. D-GalUA reductases are also found in plants, where they have a role in $\mathrm{L}$-ascorbate production. These enzymes are also NADPH-dependent (Agius et al. 2003), whereas an unspecific enzyme present in Euglena gracilis was described which also accepts NADH (Ishikawa et al. 2006).

A transcriptional activator for pectin and D-galUA catabolism, GaaR, was identified in A. niger (Alazi et al. 2016) and B. cinerea (Zhang et al. 2016b). A repressor of the GaaR, called GaaX, was identified in A. niger. Deletion of the gaaX gene resulted in strains that constitutively express GaaR-induced genes. The genes gaaX and gaaR are clustered and the clustering of these two genes is conserved in ascomycetes filamentous fungi (Niu et al. 2017). The compound that induces the transcription was 


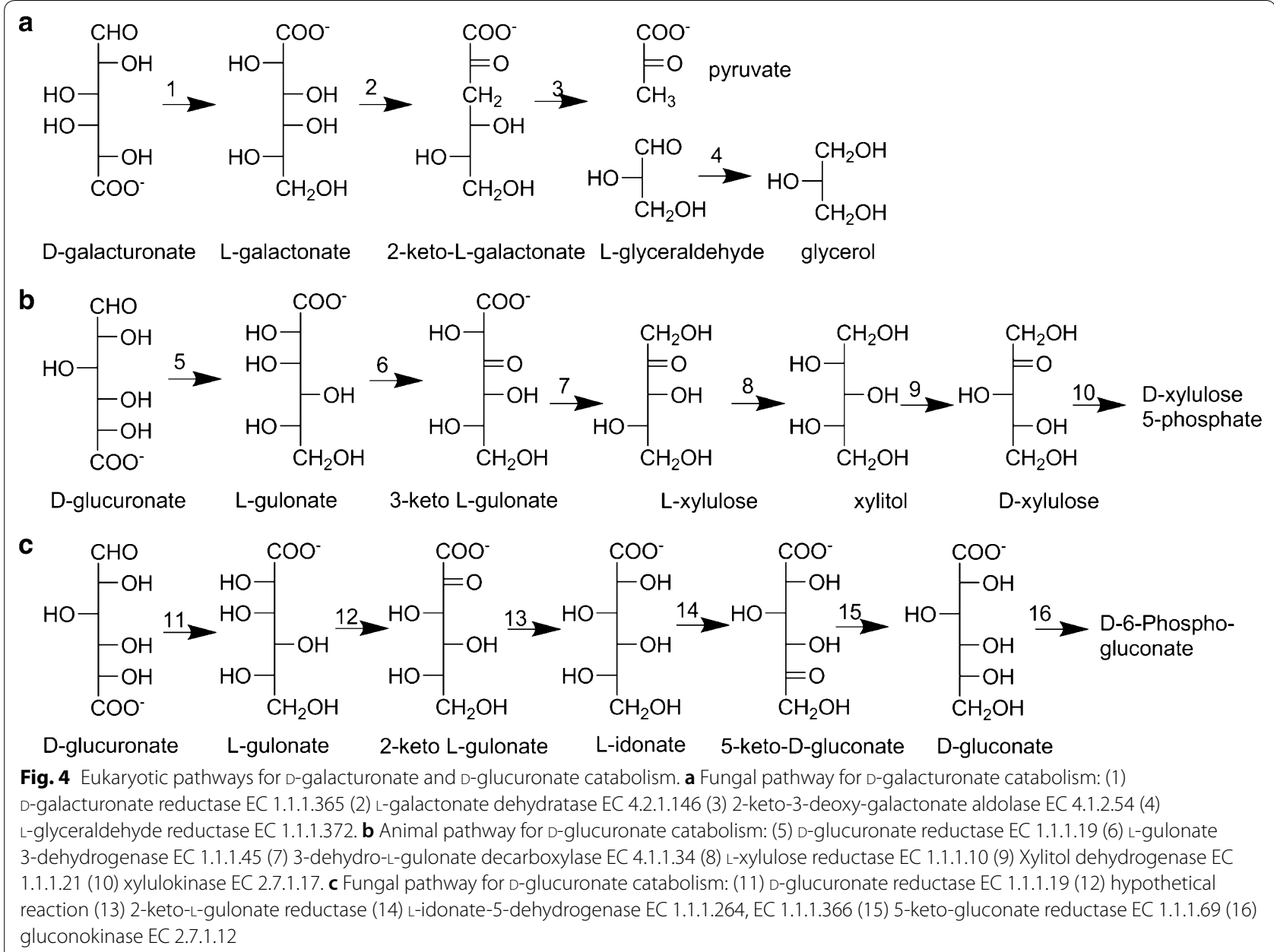

identified as D-galUA or a compound derived from it (de Vries et al. 2002), and recently as 2-keto-3-deoxy-L-galactonate (Lin and Shaw 2007; Alazi et al. 2017).

\section{Animal pathway for D-glucuronate metabolism}

D-GlcUA is a central metabolite in mammalian metabolism. It can be derived from UDP-glucuronate (Linster and Van Schaftingen 2006), from myo-inositol by the action of inositol oxygenase or from mucopolysaccharides (also referred to as glycosaminoglycans) through the action of $\alpha$ - or $\beta$-glucuronidases. D-GlcUA is catabolised through a pathway that is sometimes called the glucuronate-xylulose-pentose phosphate (GXPP) pathway (Hankes et al. 1969) or the uronate cycle. It was estimated that about $5 \%$ of glucose is metabolised through this pathway in mammals (Kaneko et al. 1997). The enzymes of this pathway are: D-glcUA reductase (EC 1.1.1.19) (Sato and Kador 1993), L-gulonate 3-dehydrogenase (EC 1.1.1.45) (Ishikura et al. 2005), 3-keto-L-gulonate decarboxylase (EC 4.1.1.34) (Smiley and Ashwell 1961) (Goode et al. 1996), L-xylulose reductase (EC 1.1.1.10) (Ishikura et al. 2001), xylitol dehydrogenase (EC 1.1.1.9) and xylulokinase (2.7.1.17). The last enzyme produces $\mathrm{D}$-xylulose-5-phosphate, which is a metabolite in the pentose phosphate pathway (Fig. 4b).

\section{Fungal pathway for D-glucuronate}

The fungal D-galUA reductases are unspecific for the substrate and also convert D-glcUA to L-gulonate. Indeed, GaaA is the first enzyme in the D-galUA as well as in the D-glcUA pathway. The other parts of the D-glcUA pathway are however completely different (Fig. 4). The L-galactonate dehydratase was specific for L-galactonate in T. reesei (Kuorelahti et al. 2006) and A. niger also does not appear to have an L-gulonate dehydratase (Motter et al. 2014). The fungal D-glucuronate pathway is not only different to the fungal D-galacturonate pathway, but is also different to the other eukaryotic path for D-glucuronate catabolism, the animal pathway. The fungal pathway for D-glcUA catabolism produces D-gluconate. The intermediates are L-gulonate, 2-keto-L-gulonate, L-idonate and 5-keto-D-gluconate. The genes and corresponding 
enzymes have been described in $A$. niger except for the reaction from $\mathrm{L}$-gulonate to 2 -keto-L-gulonate (Kuivanen et al. 2016a, 2017; Kuivanen and Richard 2018). In $A$. niger, D-gluconate is then phosphorylated to gluconate6-phosphate, which is part of the pentose phosphate pathway (Müller 1985) (Fig. 4c). There is however also one report about an alternative pathway for $\mathrm{D}$-gluconate in A. niger (Elzainy et al. 1973).

\section{Engineering hexuronate conversions in microbes D-Galacturonate uptake}

When engineering microbes which do not naturally catabolise D-galUA for D-galUA conversions, the uptake of D-galUA must be addressed. In bacteria, the ExuT is responsible for transport of the hexuronates D-galUA and D-glcUA (Nemoz et al. 1976). In fungal microorganisms, other transporters are required. The yeast Saccharomyces cerevisiae was reported to take up D-galUA in low-pH conditions, although no protein for this transport activity could be identified (Souffriau et al. 2012). A D-galUA transport protein Gat1 was identified in Neurospora crassa. This protein was expressed in S. cerevisiae. Co-expression with a D-galUA dehydrogenase (Udh) or reductase (GaaA) resulted in the production of galactarate or L-galactonate, respectively, showing that the protein does indeed facilitate the transport of D-galUA to the cytosol (Benz et al. 2014). Deletion of the gat1 gene in $N$. crassa resulted in reduced growth on pectin (Benz et al. 2014). Another transport protein was identified in Botrytis cinerea. In this case the deletion also affected growth on pectin (Zhang et al. 2014). Recently a GalUA transport protein from $A$. niger, GatA, was identified. When expressed in $S$. cerevisiae the GatA was about 50 times more active than the Gat 1 and it was not inhibited by glucose in the medium (Protzko et al. 2018).

\section{Engineering microbes for ethanol production}

D-GalUA is more oxidised than the sugars generally used for ethanol fermentation, which makes it challenging as a substrate for ethanol production. Using the bacterial isomerase pathway under anaerobic conditions would require two $\mathrm{NADH}$ per $\mathrm{D}$-galUA to produce equimolar amounts of ethanol and $\mathrm{CO}_{2}$. It was suggested to express the isomerase pathway in yeast with the aim of using the resulting strain in co-fermentations with hexose and pentose sugars (van Maris et al. 2006). During the anaerobic sugar fermentation, a significant fraction of the carbon is directed to glycerol to compensate for oxidative, NADHgenerating reactions in biosynthesis. The co-fermentation with D-galUA would provide an alternative NADH sink and would direct more carbon to ethanol (van Maris et al. 2006). Parts of the isomerase pathway have been expressed in S. cerevisiae: The genes $u x a C$ and $u x a B$ were expressed as active proteins (Huisjes et al. 2012), as well as kdgK and kdgA (Enquist-Newman et al. 2014). Expression of the complete bacterial isomerase pathway in yeast is still to be demonstrated.

In an alternative approach, the fungal D-galUA pathway, including a D-galUA transporter from $N$. crassa, was expressed in S. cerevisiae. All enzymes of the pathway were shown to be actively expressed; however, the resulting strain was not able to grow on D-galUA as the sole carbon source. Nevertheless, D-galUA was catabolized in a co-fermentation with a fermentable sugar (Biz et al. 2016). The low activity of the Lgd1 seemed to prevent growth on D-galUA. In the recent work of (Protzko et al. 2018) the Lgd1 was N-terminally tagged with a yellow fluorescence protein (Venus) resulting in a 60 fold increase in activity and resulting in growth on $\mathrm{D}$-galUA when the complete pathway was expressed.

Hexuronates from alginate were fermented to ethanol using engineered $S$. cerevisiae. Alginate was hydrolysed with alginate lyase to generate the 2-keto-3-deoxy form of D-mannuronate and L-guluronate, DEHU. The strains contained a DEHU transporter and the DEHU pathway as shown in Fig. 2. To compensate for the NADH requirement, a mannitol pathway was expressed. The resulting strains were able to co-ferment mannitol and DEHU under anaerobic conditions to ethanol, achieving yields up to $83 \%$ of the maximum theoretical yield from the consumed sugars and titres of $36 \mathrm{~g} / \mathrm{l}$ (Enquist-Newman et al. 2014).

\section{Engineering microbes for butanediol production}

For the production of butanediol from D-galUA, the oxidative pathway as in Fig. 3 was used. The pathway was introduced to $E$. coli to produce 2-keto-glutarate semialdehyde (2,5-dioxopentanoate). This was then converted by a 2-keto acid decarboxylase (KDC) and an alcohol dehydrogenase to 1,4-butanediol, which was also expressed in E. coli. Since E. coli has endogenous pathways for D-galUA and galactarate catabolism, the $u x a C$ and the garD coding for D-galUA isomerase and galactarate dehydratase, respectively, also had to be deleted. The resulting strain produced about $20 \mathrm{~g} / \mathrm{l}$ butanediol from D-galUA (Tai et al. 2016).

\section{Engineering microbes for galactarate production}

Galactarate is in itself a useful chemical. It is currently used in skin care products and was used as an acidifier in self-rising flour (Anonymus 1922). It is also the starting material for a chemical conversion to other useful chemicals, e.g. it can be quantitatively converted to adipic acid (Li et al. 2014), which is used for production of nylon.

D-GalUA acid can be oxidized to meso-galactarate in a microorganism expressing uronate dehydrogenase, udh. 
This was first demonstrated in the mould T. reesei. To prevent D-galUA catabolism, the endogenous catabolic pathway was disrupted by deleting the gene gar1 encoding D-galUA reductase and overexpressing the bacterial D-galUA dehydrogenase $u d h$ (Mojzita et al. 2010). Later on, process optimization resulted in a galactarate titre up to $20 \mathrm{~g} / \mathrm{l}$ from D-galUA (Barth and Wiebe 2017), and production from hydrolysed pectin with 18,21 and $14 \mathrm{~g} / \mathrm{l}$ galactarate titres in 1,10 and 2501 bioreactor cultivations, respectively (Paasikallio et al. 2017). A more suitable mould for the pectin conversion was considered to be $A$. niger, since this mould produces pectinases efficiently. A. niger is however able to catabolise galactarate (Mojzita et al. 2010). Eliminating the galactarate catabolism was hampered by the fact that no fungal pathway had been described. To identify the genes of that pathway, mRNA of galactarate-grown mycelia was sequenced to identify the genes that were upregulated. These genes were then deleted and three genes coding for proteins with unknown function were identified to be essential for galactarate catabolism. Elimination of galactarate catabolism in combination with the expression of a udh resulted in a strain that was capable of producing galactarate not only from $\mathrm{D}$-galUA, but also directly from pectin and CPW as a consolidated bioprocess (Kuivanen et al. 2016b).

A similar approach was made in E. coli. To prevent D-galUA and galactarate catabolism, the $u x a C$ and $\operatorname{garD}$ genes were deleted and the D-galUA dehydrogenase $u d h$ was expressed. The resulting strain converted the D-galUA quantitatively to galactarate (Zhang et al. 2016a). In addition, galactarate production was demonstrated in an engineered $S$. cerevisiae strain containing the transport protein Gat1 and Udh (Benz et al. 2014).

\section{L-Galactonic and 2-keto-3-deoxy-L-galactonic acids}

$\mathrm{L}$-Galactonate ( $\mathrm{L}-\mathrm{GalA})$, a metabolite of the fungal D-galUA pathway, is an L-sugar acid with potential use in some applications. For example, it can be converted to L-ascorbic acid, L-AA, also known as vitamin C, through biochemical (Roland et al. 1986) or chemical (Csiba et al. 1993) conversion. L-GalA can be produced from D-galUA through biochemical reduction of the aldehyde group at $\mathrm{C} 1$. This can be done using engineered strains of moulds having the disrupted L-galA dehydratase gene. The production from $D$-galUA has been demonstrated with engineered $H$. jecorina ( $T$. reesei) and $A$. niger strains (Kuivanen et al. 2012). In bioreactor experiments, the highest product titre and yield observed with the $H$. jecorina strain from pure D-galUA were $7.2 \mathrm{~g} / \mathrm{l}$ and $70 \%$ of the theoretical yield, whereas the A. niger performed less well in the same cultivation conditions (Kuivanen et al. 2012). However, low pH appears to favour L-galA production in $A$. niger. Similar titres of around $7 \mathrm{~g} / \mathrm{l}$ were produced by the engineered $A$. niger strain cultivated in shake flasks when the $\mathrm{pH}$ was decreased to 3 (Kuivanen et al. 2012). With both organisms ( $H$. jecorina and $A$. niger), the production required supplementation of a co-substrate (D-xylose) providing reducing power for the conversion. Consolidated bioprocessing from polygalacturonate (Kuivanen et al. 2012) and from citrus processing waste (Kuivanen et al. 2014) to L-galA has been demonstrated with the engineered $A$. niger strain. A. niger produces pectic enzymes and is capable of degrading pectin-rich biomass without significant biomass pretreatment steps (Kuivanen et al. 2014). In the case of polygalacturonate, around $8 \mathrm{~g} / \mathrm{l}$ of L-galA was produced from the initial $15 \mathrm{~g} / \mathrm{l}$ polygalacturonate in a bioreactor cultivation (Kuivanen et al. 2012). The consolidated bioprocess from CPW was carried out both as submerged and solid state fermentations in shake flasks and the product titres and yields were similar to those observed from pure D-galUA (Kuivanen et al. 2014). In addition to the engineered moulds, D-galUA conversion to L-galA has been demonstrated in engineered $S$. cerevisiae strains by expressing a heterologous D-galUA reductase from $A$. niger (Benz et al. 2014) or Cryptococcus diffluens (Matsubara et al. 2016).

2-Keto-3-deoxy-L-galactonic acid (2K3D-L-galA) is an intermediate of the fungal catabolic D-galUA pathway, but is also a keto-deoxy sugar with the potential of being used as a precursor for chemical synthesis. 2K3DL-galA was produced using engineered T. reesei and $A$. niger strains (Wiebe et al. 2010). Deletion of the 2K3D-LgalA aldolase-encoding gene lga 1 from $T$. reesei resulted in a strain producing $10.5 \mathrm{~g} / \mathrm{l} 2 \mathrm{~K} 3 \mathrm{D}$ - $\mathrm{L}$-galA from $20 \mathrm{~g} / \mathrm{l}$ D-galUA in a bioreactor. In addition, an $A$. niger strain with the deleted aldolase-encoding gene $\mathrm{gaaC}$ produced $15 \mathrm{~g} / \mathrm{l} 2 \mathrm{~K} 3 \mathrm{D}-\mathrm{L}-\mathrm{galA}$ from $20 \mathrm{~g} / \mathrm{l}$ polygalacturonate in a consolidated bioprocess.

\section{L-Ascorbic acid}

L-AA is widely used as an antioxidant in the food, beverage and feed industries and as a supplement in pharmaceuticals, with the annual market volume exceeding 100,000 tons (Pappenberger and Hohmann 2014). Currently, the industrial production is mainly based on a multi-step process combining chemical and biotechnological steps, in which D-glucose is converted to L-AA (Pappenberger and Hohmann 2014). A purely biotechnological one-step process could be advantageous due to lower processing costs. Recently, a one-step biochemical process converting D-galUA to L-AA was demonstrated using an engineered A. niger strain (Kuivanen et al. 2015). As in the case of L-galA-producing $A$. niger strains, the native L-galA dehydratase activity was disrupted from the D-galUA pathway 
and two heterologous genes, encoding an L-galA lactonase and an L-galactono-1,4-lactone (L-galL) dehydrogenase (GALDH), both from a plant biosynthetic L-AA pathway, were expressed. In this pathway, L-galA is first lactonized to $\mathrm{L}$-galL, followed by an oxidation reaction forming L-AA in the next step. As a result, low concentrations of L-AA, around $80 \mathrm{mg} / \mathrm{l}$ from pure D-galUA and $170 \mathrm{mg} / \mathrm{l}$ from CPW, were observed (Kuivanen et al. 2015). The majority of D-galUA in the process was converted to L-galA but not further to L-AA. Inefficiency of the lactonization reaction was considered to limit the process in the current strains (Kuivanen et al. 2015).

\author{
Abbreviations \\ D-galUA: D-galacturonate; D-gluUA: D-glucuronate; L-galA: L-galactonate; L-AA: \\ L-ascorbate; 2K3D-L-galA: 2-keto-3-deoxy-L-galactonate; DEHU: 4-deoxy- \\ L-erythro-5-hexoseulose; HG: homogalacturonan; XGA: xylogalacturonan; RGII: \\ rhamnogalacturonan II; RGI: rhamnogalacturonan I.
}

\section{Authors' contributions}

Conceptualization: PR, AB, JK; Literature review: PR, AB, JK; Writing: PR, JK. Figures: PR, JK; Funding: PR, AB. All authors read and approved the final manuscript.

\section{Author details}

${ }^{1}$ VTT Technical Research Centre of Finland Ltd, PO box 1000, 02044 VTT Espoo, Finland. ${ }^{2}$ Department of Chemical Engineering and Applied Chemistry, University of Toronto, 200 College st, Toronto, ON M5S 3E5, Canada.

\section{Acknowledgements}

We would like to thank Dr. Dorthe Rippert from the Jacobs University in Bremen for critical reading.

\section{Competing interests}

The authors declare that they have no competing interests.

\section{Availability of data and materials}

Not applicable.

\section{Consent for publication}

Not applicable.

\section{Ethics approval and consent to participate}

Not applicable.

\section{Funding}

This work was supported by the Academy of Finland through the grants 311958 (ERANET-lac: CPW Biorefinery) and 311743 (ERASynBio 2016: YEAST$\mathrm{PEC}$ ). The participation of Alessandra Biz in this work was made possible by an overseas postdoctoral fellowship (Process 207321/2015-9) conceded by CNPq (Conselho Nacional de Desenvolvimento Científico e Tecnológico), a Brazilian government agency for the advancement of science and technology.

\section{Publisher's Note}

Springer Nature remains neutral with regard to jurisdictional claims in published maps and institutional affiliations.

Received: 17 October 2018 Accepted: 23 January 2019

Published online: 30 January 2019

\section{References}

Aghaie A, Lechaplais C, Sirven P, Tricot S, Besnard-Gonnet M, Muselet D, De Berardinis V, Kreimeyer A, Gyapay G, Salanoubat M, Perret A (2008) New insights into the alternative D-glucarate degradation pathway. J Biol Chem 283:15638-15646. https://doi.org/10.1074/jbc.M800487200

Agius F, González-Lamothe R, Caballero JL, Muñoz-Blanco J, Botella MA, Valpuesta V (2003) Engineering increased vitamin C levels in plants by overexpression of a D-galacturonic acid reductase. Nat Biotechnol 21:177-181. https://doi.org/10.1038/nbt777

Alazi E, Niu J, Kowalczyk JE, Peng M, Aguilar Pontes MV, van Kan JAL, Visser J, de Vries RP, Ram AFJ (2016) The transcriptional activator GaaR of Aspergillus niger is required for release and utilization of D-galacturonic acid from pectin. FEBS Lett 590:1804-1815

Alazi E, Khosravi C, Homan TG, du Pré S, Arentshorst M, Di Falco M, Pham TTM, Peng M, Aguilar-Pontes MV, Visser J, Tsang A, de Vries RP, Ram AFJ (2017) The pathway intermediate 2-keto-3-deoxy-L-galactonate mediates the induction of genes involved in D-galacturonic acid utilization in Aspergillus niger. FEBS Lett 591:1408-1418. https://doi. org/10.1002/1873-3468.12654

Andberg M, Maaheimo H, Boer H, Penttilä M, Koivula A, Richard P (2012) Characterization of a novel Agrobacterium tumefaciens galactarolactone cycloisomerase enzyme for direct conversion of D-galactarolactone to 3-deoxy-2-keto-L-threo-hexarate. J Biol Chem. https://doi.org/10.1074/ jbc.m111.335240

Anonymus (1922) Commercial production of mucic acid. Chem Metall Eng 26:1118

Barth D, Wiebe MG (2017) Enhancing fungal production of galactaric acid. Appl Microbiol Biotechnol 101:4033-4040. https://doi.org/10.1007/s0025 3-017-8159-y

Benz JP, Protzko RJ, Andrich JM, Bauer S, Dueber JE, Somerville CR (2014) Identification and characterization of a galacturonic acid transporter from Neurospora crassa and its application for Saccharomyces cerevisiae fermentation processes. Biotechnol Biofuels 7:20. https://doi. org/10.1186/1754-6834-7-20

Biz A, Sugai-Guérios MH, Kuivanen J, Maaheimo H, Krieger N, Mitchell DA, Richard P (2016) The introduction of the fungal D-galacturonate pathway enables the consumption of D-galacturonic acid by Saccharomyces cerevisiae. Microb Cell Fact 15:144. https://doi.org/10.1186/s12934-016-0544-1

Boer H, Maaheimo H, Koivula A, Penttilä M, Richard P (2010) Identification in Agrobacterium tumefaciens of the D-galacturonic acid dehydrogenase gene. Appl Microbiol Biotechnol. https://doi.org/10.1007/s0025 3-009-2333-9

Bouvier JT, Groninger-Poe FP, Vetting M, Almo SC, Gerlt JA (2014) Galactaro $\delta$-lactone isomerase: lactone isomerization by a member of the amidohydrolase superfamily. Biochemistry 53:614-616. https://doi.org/10.1021/ bi5000492

Bouvier JT, Sernova NV, Ghasempur S, Rodionova IA, Vetting MW, Al-Obaidi NF, Almo SC, Gerlt JA, Rodionov DA (2018) Novel metabolic pathways and regulons for hexuronate utilization in proteobacteria. J Bacteriol. https:// doi.org/10.1128/jb.00431-18

Chang YF, Feingold DS (1970) D-glucaric acid and galactaric acid catabolism by Agrobacterium tumefaciens. J Bacteriol 102:85-96

Colquhoun IJ, Ralet M, Thibault J, Faulds CB, Williamson G (1994) Structure identification of feruloylated oligosaccharides from sugar-beet pulp by NMR spectroscopy. Carbohydr Res 263:243-256

Condemine G, Robert-Baudouy J (1991) Analysis of an Erwinia chrysanthemi gene cluster involved in pectin degradation. Mol Microbiol 5:2191-2202. https://doi.org/10.1111/j.1365-2958.1991.tb02149.x

Csiba M, Cleophax J, Petit S, Gero S (1993) An expedient and practical threestep synthesis of vitamin $C$ from a byproduct of the sugar industry: the L-galactono-1, 4-lactone pathway. J Org Chem 58:7281-7282

Culleton H, Mckie V, De Vries RP (2013) Physiological and molecular aspects of degradation of plant polysaccharides by fungi: what have we learned from Aspergillus? Biotechnol J 8:884-894. https://doi.org/10.1002/ biot.201200382

de Vries RP, Visser J (2001) Aspergillus enzymes involved in degradation of plant cell wall polysaccharides. Microbiol Mol Biol Rev 65:497-522. https ://doi.org/10.1128/MMBR.65.4.497

de Vries RP, Jansen J, Aguilar G, Pařenicová L, Joosten V, Wülfert F, Benen JAE, Visser J (2002) Expression profiling of pectinolytic genes from Aspergillus niger. FEBS Lett 530:41-47. https://doi.org/10.1016/S0014-5793(02)03391 
Edwards MC, Doran-Peterson J (2012) Pectin-rich biomass as feedstock for fuel ethanol production. Appl Microbiol Biotechnol 95:565-575. https://doi. org/10.1007/s00253-012-4173-2

Elzainy TA, Hassan MM, Allam AM (1973) New pathway for nonphosphorylated degradation of gluconate by Aspergillus niger. J Bacteriol 114:457-459

Enquist-Newman M, Faust AME, Bravo DD, Santos CNS, Raisner RM, Hanel A, Sarvabhowman P, Le C, Regitsky DD, Cooper SR, Peereboom L, Clark A, Martinez Y, Goldsmith J, Cho MY, Donohoue PD, Luo L, Lamberson B, Tamrakar P, Kim EJ, Villari IL, Gill A, Tripathi SA, Karamchedu P, Paredes CJ, Rajgarhia V, Kotlar HK, Bailey RB, Miller DJ, Ohler NL, Swimmer C, Yoshikuni Y (2014) Efficient ethanol production from brown macroalgae sugars by a synthetic yeast platform. Nature 505:239-243. https://doi.org/10.1038/ nature 12771

Glasson CRK, Sims IM, Carnachan SM, de Nys R, Magnusson M (2017) A cascading biorefinery process targeting sulfated polysaccharides (ulvan) from Ulva ohnoi. Algal Res 27:383-391. https://doi.org/10.1016/j.algal .2017.07.001

Goode D, Lewis ME, Crabbe MJ (1996) Accumulation of xylitol in the mammalian lens is related to glucuronate metabolism. FEBS Lett 395:174-178

Groninger-Poe FP (2014) Functional assignments in the enolase superfamily: Investigations of two divergent groups of D-galacturonate dehydratases and galactarate dehydratase-III. University of Illionois

Guillon F, Thibault J, Rombouts FM, Voragen AG, Pilnik W (1989) Enzymic hydrolysis of the "hairy" fragments of sugar-beet pectins. Carbohydr Res 190:97-108

Hankes L, Politzer W, Touster O, Anderson L (1969) Myo-inositol catabolism in human pentosurics: the predominant role of the glucuronate-xylulosepentose phosphate pathway. Ann N Y Acad Sci 165:564-576

Hantz O (1977) La voie dégradative secondaire du 2 céto 3 desoxygluconate chez Escherichia coli. Oxydation enzymatique du 2 céto 3 desoxygluconate. Dissertation, Claude Bernard University

Hilditch S, Berghäll S, Kalkkinen N, Penttilä M, Richard P (2007) The missing link in the fungal D-galacturonate pathway. J Biol Chem 282:26195-26201. https://doi.org/10.1074/jbc.M704401200

Hobbs JK, Lee SM, Robb M, Hof F, Barr C, Abe KT, Hehemann J-H, McLean R, Abbott DW, Boraston AB (2016) KdgF, the missing link in the microbial metabolism of uronate sugars from pectin and alginate. Proc Natl Acad Sci 113:6188-6193. https://doi.org/10.1073/pnas.1524214113

Huisjes EH, Luttik MAH, Almering MJH, Bisschops MMM, Dang DHN, Kleerebezem M, Siezen R, van Maris AJA, Pronk JT (2012) Toward pectin fermentation by Saccharomyces cerevisiae: expression of the first two steps of a bacterial pathway for D-galacturonate metabolism. J Biotechnol 162:303-310. https://doi.org/10.1016/j.jbiotec.2012.10.003

Ishikawa T, Masumoto I, Iwasa N, Nishikawa H, Sawa Y, Shibata H, Nakamura A, Yabuta Y, Shigeoka S (2006) Functional characterization of D-galacturonic acid reductase, a key enzyme of the ascorbate biosynthesis pathway, from Euglena gracilis. Biosci Biotechnol Biochem 70:2720-2726. https:// doi.org/10.1271/bbb.60327

Ishikura S, Isaji T, Usami N, Kitahara K, Nakagawa J, Hara A (2001) Molecular cloning, expression and tissue distribution of hamster diacetyl reductase. Identity with L-xylulose reductase. Chem Biol Interact 130-132:879-889

Ishikura S, Usami N, Araki M, Hara A (2005) Structural and functional characterization of rabbit and human L-gulonate 3-dehydrogenase. J Biochem 137:303-314. https://doi.org/10.1093/jb/mvi033

Kaneko JJ, Harvey JW, Bruss M (1997) Clinical chemistry of domestic animals. Academic Press, San Diego

Khanh NQ, Ruttkowski E, Leidinger K, Albrecht H, Gottschalk M (1991) Characterization and expression of a genomic pectin methyl esterase-encoding gene in Aspergillus niger. Gene 106:71-77

Kuivanen J (2015) Metabolic engineering of the fungal D-galacturonate pathway. Aalto University, Helsinki

Kuivanen J, Richard P (2018) NADPH-dependent 5-keto-D-gluconate reductase is a part of the fungal pathway for D-glucuronate catabolism. FEBS Lett. https://doi.org/10.1002/1873-3468.12946

Kuivanen J, Mojzita D, Wang Y, Hilditch S, Penttilä M, Richard P, Wiebe MG (2012) Engineering filamentous fungi for conversion of D-galacturonic acid to L-galactonic acid. Appl Environ Microbiol 78:8676-8683

Kuivanen J, Dantas H, Mojzita D, Mallmann E, Biz A, Krieger N, Mitchell D, Richard P (2014) Conversion of orange peel to L-galactonic acid in a consolidated process using engineered strains of Aspergillus niger. AMB Express 4:33
Kuivanen J, Penttilä M, Richard P (2015) Metabolic engineering of the fungal D-galacturonate pathway for L-ascorbic acid production. Microb Cell Fact 14:1-9. https://doi.org/10.1186/s12934-014-0184-2

Kuivanen J, Sugai-Guérios MH, Arvas M, Richard P (2016a) A novel pathway for fungal D-glucuronate catabolism contains an L-idonate forming 2-ketoL-gulonate reductase. Sci Rep 6:26329. https://doi.org/10.1038/srep26329

Kuivanen J, Wang Y-MJ, Richard P (2016b) Engineering Aspergillus niger for galactaric acid production: elimination of galactaric acid catabolism by using RNA sequencing and CRISPR/Cas9. Microb Cell Fact 15:210. https:// doi.org/10.1186/s12934-016-0613-5

Kuivanen J, Arvas M, Richard P (2017) Clustered genes encoding 2-ketoL-gulonate reductase and $\mathrm{L}$-idonate 5 -dehydrogenase in the novel fungal D-glucuronic acid pathway. Front Microbiol. https://doi.org/10.3389/ fmicb.2017.00225

Kuorelahti S, Kalkkinen N, Penttilä M, Londesborough J, Richard P (2005) Identification in the mold Hypocrea jecorina of the first fungal D-galacturonic acid reductase. Biochemistry. https://doi.org/10.1021/bi050792f

Kuorelahti S, Jouhten P, Maaheimo H, Penttilä M, Richard P (2006) L-galactonate dehydratase is part of the fungal path for $\mathrm{D}$-galacturonic acid catabolism. Mol Microbiol 61:1060-1068. https://doi.org/10.111 $1 / j .1365-2958.2006 .05294 . x$

Lahaye M, Robic A (2007) Structure and function properties of Ulvan, a polysaccharide from green seaweeds. Biomacromol 8:1765-1774. https://doi. org/10.1021/bm061185q

Li X, Wu D, Lu T, Yi G, Su H, Zhang Y (2014) Highly efficient chemical process to convert mucic acid into adipic acid and DFT studies of the mechanism of the rhenium-catalyzed deoxydehydration. Angew Chemie Int Ed 53:4200-4204. https://doi.org/10.1002/anie.201310991

Liepins J, Kuorelahti S, Penttilä M, Richard P (2006) Enzymes for the NADPHdependent reduction of dihydroxyacetone and D-glyceraldehyde and L-glyceraldehyde in the mould Hypocrea jecorina. FEBS J 273:4229-4235. https://doi.org/10.1111/j.1742-4658.2006.05423.x

Lin JS, Shaw GC (2007) Regulation of the kdulD operon of Bacillus subtilis by the KdgR repressor and the ccpA gene: identification of two KdgRbinding sites within the kdgR-kdul intergenic region. Microbiology 153:701-710. https://doi.org/10.1099/mic.0.2006/002253-0

Linster CL, Van Schaftingen E (2006) Glucuronate, the precursor of vitamin C, is directly formed from UDP-glucuronate in liver. FEBS J 273:1516-1527. https://doi.org/10.1111/j.1742-4658.2006.05172.x

Martens-Uzunova ES, Schaap PJ (2008) An evolutionary conserved D-galacturonic acid metabolic pathway operates across filamentous fungi capable of pectin degradation. Fungal Genet Biol 45:1449-1457. https://doi. org/10.1016/j.fgb.2008.08.002

Martens-Uzunova ES, Schaap PJ (2009) Assessment of the pectin degrading enzyme network of Aspergillus niger by functional genomics. Fungal Genet Biol 46:170-179

Matsubara T, Hamada S, Wakabayashi A, Kishida M (2016) Fermentative production of L-galactonate by using recombinant Saccharomyces cerevisiae containing the endogenous galacturonate reductase gene from Cryptococcus diffluens. J Biosci Bioeng 122:639-644. https://doi.org/10.1016/j. jbiosc.2016.05.002

Mekjian KR, Bryan EM, Beall BW, Moran CP (1999) Regulation of hexuronate utilization in Bacillus subtilis. J Bacteriol 181:426-433

Micard V, Renard CMGC, Thibault J (1996) Enzymatic saccharification of sugarbeet pulp. Enzym Micobial Technol 19:162-170

Mohnen D (2008) Pectin structure and biosynthesis. Curr Opin Plant Biol 11:266-277. https://doi.org/10.1016/j.pbi.2008.03.006

Mojzita D, Wiebe M, Hilditch S, Boer H, Penttilä M, Richard P (2010) Metabolic engineering of fungal strains for conversion of $\mathrm{D}$-galacturonate to mesogalactarate. Appl Environ Microbiol 76:169-175. https://doi.org/10.1128/ AEM.02273-09

Moon TS, Yoon S-H, Lanza AM, Roy-Mayhew JD, Prather KLJ (2009) Production of glucaric acid from a synthetic pathway in recombinant Escherichia coli. Appl Environ Microbiol 75:589-595. https://doi.org/10.1128/AEM.00973 $-08$

Motter FA, Kuivanen J, Keränen H, Hilditch S, Penttilä M, Richard P (2014) Categorisation of sugar acid dehydratases in Aspergillus niger. Fungal Genet Biol 64:67-72. https://doi.org/10.1016/j.fgb.2013.12.006

Müller H-M (1985) Utilization of gluconate by Aspergillus niger. I. Enzymes of phosphorylating and nonphosphorylating pathways. Zentralbl Mikrobiol 140:475-484. https://doi.org/10.1016/S0232-4393(85)80054-8 
Nemoz G, Robert-Baudouy J, Stoeber F (1976) Physiological and genetic regulation of the aldohexuronate transport system in Escherichia coli. J Bacteriol 127:706-718

Niu J, Alazi E, Reid ID, Arentshorst M, Punt PJ, Visser J, Tsang A, Ram AFJ (2017) An evolutionarily conserved transcriptional activator-repressor module controls expression of genes for D-galacturonic acid utilization in Aspergillus niger. Genetics 205:169-183. https://doi.org/10.1534/genet iCs.116.194050

O'Neill MA, Ishii T, Albersheim P, Darvill AG (2004) Rhamnogalacturonan II: structure and function of a borate cross-linked cell wall pectic polysaccharide. Annu Rev Plant Biol 55:109-139

Paasikallio T, Huuskonen A, Wiebe MG (2017) Scaling up and scaling down the production of galactaric acid from pectin using Trichoderma reesei. Microb Cell Fact 16:119. https://doi.org/10.1186/s12934-017-0736-3

Pappenberger G, Hohmann H-P (2014) Industrial production of L-ascorbic acid (vitamin C) and D-isoascorbic acid. Adv Biochem Eng Biotechnol 143:143-188. https://doi.org/10.1007/10_2013_243

Parkkinen T, Boer H, Jänis J, Andberg M, Penttilä M, Koivula A, Rouvinen J (2011) Crystal structure of uronate dehydrogenase from Agrobacterium tumefaciens. J Biol Chem 286:27294-27300. https://doi.org/10.1074/jbc. M111.254854

Preiss J, Ashwell G (1962) Alginic acid metabolism in bacteria. J Biol Chem 237:317-321

Protzko RJ, Latimer LN, Martinho Z, de Reus E, Seibert T, Benz JP, Dueber JE (2018) Engineering Saccharomyces cerevisiae for co-utilization of D-galacturonic acid and D-glucose from citrus peel waste. Nat Commun 9:5059. https://doi.org/10.1038/s41467-018-07589-w

Reis D, Vian B, Roland JJ-C, Boon ME, Leyden P, De Phytopathologie L (1994) Cellulose-glucuronoxylans and plant cell wall structure. Micron 25:171187. https://doi.org/10.1016/0968-4328(94)90041-8

Richard P, Hilditch S (2009) D-Galacturonic acid catabolism in microorganisms and its biotechnological relevance. Appl Microbiol Biotechnol. https:// doi.org/10.1007/s00253-009-1870-6

Rodionova IA, Scott DA, Grishin NV, Osterman AL, Rodionov DA (2012) Tagaturonate-fructuronate epimerase UxaE, a novel enzyme in the hexuronate catabolic network in Thermotoga maritima. Environ Microbiol 14:2920-2934. https://doi.org/10.1111/j.1462-2920.2012.02856.x

Roland JF, Cayle T, Dinwoodie RC, Mehnert DW (1986) Fermentation production of ascorbic acid from L-galactonic substrate

Rothe M, Alpert C, Loh G, Blaut M (2013) Novel insights into E. coli's hexuronate metabolism: Kdul facilitates the conversion of galacturonate and glucuronate under osmotic stress conditions. PLoS ONE 8:1. https://doi. org/10.1371/journal.pone.0056906

Sato S, Kador PF (1993) Human kidney aldose and aldehyde reductase. J Diabetes Complications 7:179-187
Searle-van Leeuwen M, Vincken J, Schipper D, Voragen A, Beldman G (1996) Acetyl esterases of Aspergillus niger: purification and mode of action on pectins. Prog Biotechnol 14:793-798

Smiley JD, Ashwell G (1961) Purification and properties of ß-I-hydroxy acid dehydrogenase: II. isolation of ß-keto-L-gulonic acid, an intermediate in L-xylulose biosynthesis. J Biol Chem 236:357-364

Souffriau B, den Abt T, Thevelein JM (2012) Evidence for rapid uptake of D-galacturonic acid in the yeast Saccharomyces cerevisiae by a channel-type transport system. FEBS Lett 586:2494-2499. https://doi. org/10.1016/j.febslet.2012.06.012

Tai Y-S, Xiong M, Jambunathan P, Wang J, Wang J, Stapleton C, Zhang K (2016) Engineering nonphosphorylative metabolism to generate lignocellulosederived products. Nat Chem Biol 12:247-253. https://doi.org/10.1038/ nchembio.2020

Tubeleviciute A, Teese MG, Jose J (2014) Escherichia coli kduD encodes an oxidoreductase that converts both sugar and steroid substrates. Appl Microbiol Biotechnol 98:5471-5485. https://doi.org/10.1007/s0025 3-014-5551-8

van der Vlugt-Bergmans CJ, Meeuwsen PJ, Voragen AG, van Ooyen AJ (2000) Endo-xylogalacturonan hydrolase, a novel pectinolytic enzyme. Appl Environ Microbiol 66:36-41

van Maris AJA, Abbott DA, Bellissimi E, van den Brink J, Kuyper M, Luttik MAH, Wisselink HW, Scheffers WA, van Dijken JP, Pronk JT (2006) Alcoholic fermentation of carbon sources in biomass hydrolysates by Saccharomyces cerevisiae: current status. Antonie van Leeuwenhoek Int J Gen Mol Microbiol 90:391-418. https://doi.org/10.1007/s10482-006-9085-7

Wiebe MG, Mojzita D, Hilditch S, Ruohonen L, Penttilä M (2010) Bioconversion of D-galacturonate to keto-deoxy-L-galactonate (3-deoxy-L-threo-hex2-ulosonate) using filamentous fungi. BMC Biotechnol 10:63. https://doi. org/10.1186/1472-6750-10-63

Zhang L, Thiewes H, van Kan JAL (2011) The D-galacturonic acid catabolic pathway in Botrytis cinerea. Fungal Genet Biol 48:990-997. https://doi. org/10.1016/j.fgb.2011.06.002

Zhang L, Hua C, Stassen JHM, Chatterjee S, Cornelissen M, van Kan JAL (2014) Genome-wide analysis of pectate-induced gene expression in Botrytis cinerea: identification and functional analysis of putative $\mathrm{D}$-galacturonate transporters. Fungal Genet Biol 72:182-191. https://doi.org/10.1016/j. fgb.2013.10.002

Zhang H, Li X, Su X, Ang EL, Zhang Y, Zhao H (2016a) Production of adipic acid from sugar beet residue by combined biological and chemical catalysis. ChemCatChem 8:1500-1506. https://doi.org/10.1002/cctc.201600069

Zhang L, Lubbers RJM, Simon A, Stassen JHM, Vargas Ribera PR, Viaud M, Van Kan JAL (2016b) A novel Zn2Cys6transcription factor BcGaaR regulates D-galacturonic acid utilization in Botrytis cinerea. Mol Microbiol 100:247-262. https://doi.org/10.1111/mmi.13314

\section{Submit your manuscript to a SpringerOpen ${ }^{\odot}$ journal and benefit from:}

- Convenient online submission

- Rigorous peer review

- Open access: articles freely available online

- High visibility within the field

Retaining the copyright to your article

Submit your next manuscript at springeropen.com 